\title{
1 Temporal trait plasticity and neighborhood crowding predict the growth of tropical trees
}

3 Mengesha Asefa ${ }^{1,2 £}$, Xiaoyang Song ${ }^{1,3 £}$, Min Cao $^{1}$, Jesse R. Lasky ${ }^{4}$, Jie Yang ${ }^{1,2} *$

$5{ }^{1}$ CAS Key Laboratory of Tropical Forest Ecology, Xishuangbanna Tropical Botanical Garden,

6 Chinese Academy of Sciences, Mengla, 666303, China

$7{ }^{2}$ Center of Plant Ecology, Core Botanical Gardens, Chinese Academy of Sciences, Mengla,

8666303 , China

$9{ }^{3}$ Center of Conservation Biology, Core Botanical Gardens, Chinese Academy of Sciences,

10 Mengla, 666303, China

$11{ }^{4}$ Department of Biology, Pennsylvania State University, University Park, PA 16802 USA

12

$13{ }^{£}$ These authors contributed equally to this work.

$14 *$ Corresponding author: Jie Yang

15 Address: CAS Key Laboratory of Tropical Forest Ecology, Xishuangbanna Tropical Botanical

16 Garden, Chinese Academy of Sciences, Kunming, Yunnan, 666303, China

17 E-mail: yangjie@xtbg.org.cn

\section{Abstract}

19 Functional traits and neighborhood composition have been used to predict tree growth dynamics.

20 Temporal changes in trait values (temporal trait plasticity) is one of the mechanisms for adaptive

21 plastic response to environmental change. However, the consequence of temporal change in trait

22 values and neighborhoods on the growth performance of individuals has rarely been investigated.

23 We, therefore tested the effect of temporal changes in trait values and neighborhood crowding on 
24 the growth rate of individuals in a tropical forest using a dataset containing individual level

25 growth and functional trait data for Ficus individuals. We collected trait and size data at two time

26 points (2010 and 2017) for 472 individuals of 15 Ficus species in Xishuangbanna tropical forest

27 dynamics plot, southwest China. We used linear mixed effect model to predict the effect of

28 temporal trait plasticity and neighborhood crowding on the relative growth rate of individuals

29 using these data. We found significant temporal changes in individuals' functional traits

30 suggesting a shift in ecological strategies from being functionally acquisitive to conservative. We

31 also found differences in neighborhood crowding between the two census years indicating that

32 the strength of individual interactions might change over time. The temporal changes in trait

33 values and neighborhood crowding were found to predict better the relative growth rate of

34 individuals, compared to static trait or crowding values in the initial and final censuses. We also

35 found major axes of tree functional strategies in a principal component analysis, highlighting

36 potentially adaptive trait differences. Our results in general highlight to consider the temporal

37 dimension of functional traits and biotic interactions, as our result suggest that growth-trait

38 relationships may vary between time points, allowing us to understand the demographic response

39 of species to temporal environmental change.

41 Key words: Ficus, functional traits, forest temporal dynamics, neighborhood crowding, species

42 growth, temporal trait plasticity, tropical trees. 


\section{INTRODUCTION}

48 Biotic interactions and environmental heterogeneity overlap spatially and temporally in effects

49 on community assembly, creating dynamic and ecologically complex tropical forest community

50 (Wright 2002; Zambrano et al. 2017). Biotic interactions at local scales partly drive the

51 demographic pattern of species that ultimately shape tree community assembly (Fortunel et al.

52 2018). Heterogenous abiotic environments also sort species based on species ecological

53 requirements, and regulate species performance and community dynamics in diverse systems

54 (Lasky et al. 2013). Functional traits have been widely used to make inferences about community

55 dynamics, as traits are believed to provide insights into the role of environment in assembly

56 (Poorter and Bongers 2006; Yang et al. 2018). Although testing trait-growth relationships has

57 become more common and fundamental to understand community dynamics (Swenson et al.

58 2017), a remaining goal is to understand this relationship from a temporal perspective.

In practice, community trait data are often collected only at a single time point. These

60 static data are then used for downstream analyses to species demography and to understand

61 community change through time and space (Swenson et al. 2017). While collecting a single

62 timepoint of trait data may be pragmatic, particularly in diverse systems, a vast evolutionary

63 ecology literature shows how traits influence individual performance (Lande and Arnold 1983,

64 Wade and Kalisz 1990), and how traits change in adaptive (Moran 1992, Baythavong 2011), and

65 maladaptive response to environment (Ghalambor et al. 2007). Furthermore, traditional

66 implementation of correlating community variation in traits to demographic traits may lead to

67 weak or mislead models and inferences (Umaña et al. 2018). How trait values and neighborhood

68 interactions change over time, and how their temporal changes impact trees demography have

69 not been widely tested, despite the fact that species interactions and growth strategies are known 
70 to be temporally dynamic. This may reflect the limitation of trait-based ecology as it usually

71 gives static trait values for individuals that ignores the temporal variation of traits, and this limits

72 the ability to understand how temporal variability in traits and biotic interactions regulates the

73 performance of individuals over time (Swenson et al. 2017).

Adaptive phenotypic plasticity, i.e. when trait changes increase fitness, is a key strategy

75 by which organisms respond to changes in their environment (Pigliucci 2001). Maladaptive

76 plasticity, which is a symptom of a failure of an organism to maintain homeostasis, could also be

77 resulted when a change in trait values through time reduce fitness of organisms (Ghalambor et al.

78 2007). Temporal trait plasticity is expected to increase as conditions vary over time (Lázaro-

79 Nogal et al. 2015). Long-lived organisms have to have some level of adaptive plasticity to

80 survive and persist through such a wide range of conditions over their lifespan, relative to short

81 lifespan organisms such as annual plants. While a growing evolutionary ecology literature has

82 tested for the effects of trait plasticity on intraspecific fitness variation (Dudley and Schmitt

83 1996, Van Kleunen and Fischer 2005), less is known about how temporal trait plasticity

84 influences community assembly. Much of the earlier trait-based studies have focused on

85 assessing forest community dynamics using traits measured once in the life span of trees that

86 lacks the temporal domain of ecology (e.g., Wright et al. 2010, Lasky et al. 2014a, Paine et al.

87 2015, Visser et al. 2016). Temporal trait variation of communities has been less studied than

88 temporal shifts in species composition, though traits are known to be temporally dynamic

89 (Enquist and Enquist 2011, Fauset et al. 2012). Few studies have characterized the temporal trait

90 changes and associated demographic consequences at community level. Van Der Sande et al.

91 (2016) reported that community trait values (wood density increased; specific leaf area

92 decreased) changed over time in all of the five studied forest types in the Neotropics suggesting 
93 that species shifted from being fast-growing to slow-growing species. Temporal shifts of trait

94 distributions, mainly at the community level, have also been reported (Lasky et al. 2014b,

95 Katabuchi et al. 2017). The decrease of specific leaf area (SLA) and leaf phosphorus content

96 over time in the wet tropical forests also suggested a change in functional strategies of species

97 (Muscarella et al. 2017). A long-term shift of species' mean trait values through time showing

98 directional change was also found in a tropical dry forest (Swenson et al. 2020). There are many

99 studies that have inferred functional turnover in forests through time, using traits measured at a

100 single time point and assumed to be the same for all individuals of a species. However, these

101 studies did not measure traits of individual plants, meaning that trait plasticity could not be

102 quantified. Testing whether the effect of traits on tree growth differs between time points and

103 how the temporal shift of traits (i.e. temporal trait plasticity) plays a role in shaping the growth

104 dynamics of communities may help to better understand the direction of forest structural and

105 functional change.

106 Trait-growth relationships have been used to reveal plant growth strategies and predict

107 the demographic trajectories of species (Adler et al. 2013, Yang et al. 2020 in press). However,

108 the predictive power of traits has been sometimes weak which raises a question about the

109 significance of traits (Paine et al. 2015). One reason for this could be, apart from the trade-offs

110 between demographic rates that may conceal the effect of traits on species performance

111 (Laughlin et al. 2020 in press), trait-growth relationships usually are computed at the species

112 level using mean trait values and mean growth rates of individuals, despite the fact that trait-

113 driven resource competition occurs at the individual level (Liu et al. 2016). Averaging trait

114 values of individuals across the species ignores individual level trait variation, limiting the ability

115 of traits to predict individual growth rates (Liu et al. 2016, Umaña et al. 2018). Individuals traits 
116 may predict better the growth performance of individuals, as trait differences determine

117 individuals' growth strategies (Yang et al. 2018, Worthy \& Swenson 2019).

118 Neighborhood interactions influence tree growth, and can promote species diversity

119 (Lasky et al. 2014b, Chen et al. 2016, Lamanna et al. 2017, Zambrano et al. 2017, Fortunel et al.

120 2018). The growth rate of individuals depends on the density of immediate neighbors with

121 positive or negative effects. High density of neighbors often reduces the growth or survival rate

122 of trees (Comita et al. 2010, Johnson et al. 2017, Lamanna et al. 2017). However, studies of

123 neighborhood interactions have rarely considered temporal dynamics in biotic interactions. That

124 is, how do neighborhood interactions change over time, and do these changes affect individual

125 vital rates? Changes in neighborhoods over time, if overlooked, might obscure the effects of

126 neighbors on individual growth (Bachelot et al. 2015). The number and identity of neighbors

127 could change through time due to recruitment and mortality, and as a result the strength of

128 neighborhood effect on growth may change over time (Newbery and Stoll 2013). One of the

129 challenges of using neighborhood crowding covariates is that neighborhoods may change

130 spatially in response to variation in resources (light, water, nutrients), so that the actual available

131 resource supply might differ from what we expect from the level of crowding. And so, it may be

132 that neighborhood dynamics are better at capturing the variation in actual resource availability,

133 because we might expect an increase in crowding over time actually does correspond to less

134 available resources to individuals. Thus, the effect of neighbors may not be captured unless

135 changes in local neighborhoods are considered. However, the temporal change in neighbors and

136 its subsequent effect on tree demography has not been widely studied, though few studies being

137 reported. 
We tested how changes in functional traits and neighborhood interactions affect the

139 growth of species in the diverse genus of Ficus trees in a tropical forest. We asked the following

140 specific questions: (i) How do traits, neighborhood crowding, and growth rate of individual trees

141 change over time? (ii) Are functional traits and neighborhood crowding temporally consistent in

142 predicting the relative growth rate of individuals? (iii) Does temporal trait plasticity and changes

143 in neighborhood crowding predict better the relative growth rate of individuals compared to

144 using only a single snapshot of traits and neighborhood crowding?

\section{METHODS}

\section{Study site}

148 We carried out this study in the 20-ha Xishuangbanna seasonal tropical rainforest dynamics plot 149 (FDP) in southwest China $\left(21^{\circ} 37^{\prime} 08^{\prime \prime} \mathrm{N}, 101^{\circ} 35^{\prime} 07^{\prime \prime} \mathrm{E}\right)$ (Figure S1). Dry and rainy seasons are

150 typical features of the region with mean annual rainfall and temperature of $1493 \mathrm{~mm}$ and $21.8^{\circ} \mathrm{C}$

151 respectively (Cao et al. 2006). The plot ranges from 709 to $869 \mathrm{~m}$ in elevation (Lan et al. 2009).

152 In 2007, all free-standing woody stems $\geq 1 \mathrm{~cm}$ in diameter at $130 \mathrm{~cm}$ from the ground (Diameter

153 at Breast Height, DBH) were measured, mapped and identified to species (Condit 1998).

\section{Focal species}

156 We used the Ficus (Moraceae) genus as a case study, as it is a pantropical genus with more than

157800 species in the lowland tropical forest and contains functionally diverse species (Harrison

158 2005). Ficus assemblages provides a useful system to investigate the mechanisms that maintain

159 high tropical species diversity (Lasky et al. 2014a). Furthermore, Ficus is the most speciose

160 genus in the 20-ha plot, with 15 identified species and $4.6 \%$ of the total basal area in the plot, and 
161 a large quantity of soil seedbank (Tang et al. 2006). Most of the individuals are distributed on the

162 steep slopes of the plot, and some of them are limited to ridges and valleys (Hu et al. 2012). In

1632010 , leaf functional traits were measured on Ficus individuals with a DBH of at least $10 \mathrm{~cm}$

164 with leaves accessible with pole shears (Lasky et al. 2014a) and then re-measured these trees in

165 2017. Thus, we used trait data for the Ficus trees separated by seven years and DBH data

166 separated by ten years interval in the Xishuangbanna FDP. A species list is given in Table S1.

\section{Functional traits}

169 We measured eight functional traits data in two census years for the 472 individuals of the 15

170 Ficus species in the plot. We collected five matured, healthy and sun exposed leaves for each

171 individual in each census year and measured traits following the standardized protocols

172 (Cornelissen et al. 2003). We measured leaf area $\left(\mathrm{cm}^{2}\right)$, specific leaf area $\left(\mathrm{cm}^{2} \cdot \mathrm{g}^{-1}\right)$, leaf

173 chlorophyll content, leaf fresh mass (g), leaf dry mass (g), leaf dry mass content, leaf thickness

$174(\mathrm{~mm})$, and leaf succulence $\left(\mathrm{g} \cdot \mathrm{cm}^{-2}\right)$. These traits are expected to represent the fundamental

175 ecological strategies of individuals for resource acquisition. Leaf area is related to light capture

176 and heat balance (Poorter and Rozendaal 2008). Specific leaf area is linked to light interception

177 efficiency and the main part of leaf economic spectrum (Wright et al. 2004). Leaf chlorophyll

178 content is related to light harvesting capacity of the plant (Coste et al. 2010). Leaf thickness is

179 related to the mechanical strength of the leaf (Onoda et al. 2011). Leaf dry matter content is

180 associated with leaf defense ability and decomposition (Van Der Sande et al. 2016). Leaf

181 succulence represents the trade-off of productivity and life span of the leaf (Garnier and Laurent

182 1994). We measured the leaf chlorophyll content using SPAD-502 Chl meter (Minolta Camera

183 Co., Osaka, Japan), and three readings were taken at the widest portion of the leaf blades 
184 (Marenco et al. 2009). We used electronic digital micrometer to measure leaf thickness (mm) at

185 the center of fresh leaves with multiple readings, and average was taken (Seelig et al. 2012).

\section{Tree growth}

188 All Ficus individuals' diameter at breast height (DBH) was measured in the Xishuangbanna FDP

189 in 2007 and 2017. Relative growth rates (RGR) used in this study were calculated as

$190 \ln \left(\frac{D B H_{f} / D B H_{i}}{t_{f}-t_{i}}\right)$, where $t$ is year and the subscripts of $f$ and $i$ are respectively the final and initial

191 values of the diameter at breast height (Wright et al. 2010). The relative growth rate of species is

192 graphically indicated in Figure S2.

\section{Neighborhood crowding}

194 Neighborhood competition is one of the biotic driving forces that largely determines the growth 195 performance of individuals at the local scale (Fortunel et al. 2018). The effect of neighborhood

196 crowding is expected to decline with distance increases from the focal stem (Uriarte et al. 2010).

197 Here, we calculated the neighborhood competition of trees using the neighborhood crowding

198 index (NCI) separately for the two census years in order to evaluate its temporal effect on tree

199 growth. We computed the neighborhood crowding index (NCI) for each focal stem $i$ of species $s$

200 based on the size $(\mathrm{DBH})$ and distance $(\mathrm{d})$ of its neighbors $(j=1 \ldots J)$ within a $15 \mathrm{~m}$ radius for each

201 census year (t) (Lasky et al. 2014b, Uriarte et al. 2016). We excluded focal stems within $15 \mathrm{~m}$ of

202 plot boundaries to avoid edge effects in our analysis. A $15 \mathrm{~m}$ radius was chosen following the

203 previous work (Yang et al. 2020 in press).

$$
N C I_{t s i}=\sum_{j=1, i \neq j}^{J} \frac{D B H^{2}}{d_{i j}^{2}}
$$




\section{Statistical analyses}

\section{The temporal shift in traits and neighborhood crowding}

206 We first tested whether there were temporal shifts in traits (i.e. plasticity) and neighborhood

207 crowding over time. We used a linear mixed model to test whether significant changes in

208 univariate traits and NCI values occurred between the two censuses, with census as fixed effect

209 and the variable of interest, and species identity as random factor. Furthermore, we also used the

210 principal component analysis (PCA) on the mean centered and standardized trait values (by

211 dividing the centered trait values by their standard deviations) to find major axes of trait

212 variation and trait plasticity using the two censuses data.

213 Since functional traits were sampled twice over time on the same individuals,

214 we were able to compare the magnitude of trait variation explained by different sources. Using

215 traits as response variables, we included leaves, individuals, species, and census interval as

216 random variables in our mixed-effect models to decompose and estimate the variance explained

217 by each random variable, and expressed it in percentage as the total variance explained by each

218 of the random components. We standardized all parameters by subtracting the minimum value

219 from each observed value and then divided by its range value for the ease of interpretation and

220 comparisons. Data transformation was done for all functional traits, and other variables to meet

221 the assumption of normal distribution before analysis. Pearson correlation was carried out to

222 check for trait covariation and hence we removed leaf fresh mass from analysis as it strongly

223 correlated to leaf dry mass (Table S2, S3, and S4). 


\section{Effect of functional traits and neighborhood crowding on tree growth}

228 The second objective of this study was to evaluate the relative importance of each functional trait

229 and neighborhood crowding on the relative growth rate of individuals. To address this question,

230 we built three different models: one model using the first census data, second model using the

231 second census data, third model is using the temporal changes in trait and neighborhood

232 crowding (i.e. the difference of traits, and neighborhood crowding between the first and second

233 census data). For each model, we fitted individual RGR as a function of traits and neighborhood

234 crowding using linear mixed-effects model. To handle model complexity, we fit separately the

235 growth model for each functional trait. The first two models take the following form:

$$
R G R_{i}=\beta_{0}+\beta_{1} d b h_{0}+\beta_{2} \text { traits }_{i, t}+\beta_{3} N C I_{i, t}
$$

236 Where $d b h_{0}$ is the initial tree size $(\mathrm{DBH})$ at the first census year, traits $_{i, t}$ represents the trait

237 values of individual $i$ in year t. $N C I_{i, t}$ represents the $N C I$ values of individual $i$ in year t. $\beta_{0}$ is the

238 intercept for all individuals. For the third model, though it is the same in form with the above

239 model, we took the temporal difference in traits and NCI values. We subtracted the traits/NCI

240 values in 2010 from the corresponding values in 2017 (trait/NCI values in 2017 - trait/NCI

241 values in 2010), and were used to describe temporal changes in traits/NCI values. We selected

242 among models using Akaike Information Criterion (AIC) (Table S5, S6, and S7).

243 Additionally, we used piecewise structural equation models (SEMs) to determine any

244 possible pathways by which traits, neighborhood crowding and initial DBH size could

245 interactively influence the relative growth rate of individuals. We hypothesized that initial DBH

246 size and neighborhood crowding affect individuals' growth indirectly through their effects on

247 functional traits. Also, the DBH size may determine the canopy position and crowding

248 conditions of trees which may in turn influence trait expressions and ultimately affect growth of 
249 individuals. We computed a series of piecewise SEMs separately for each census data (i.e. $1^{\text {st }}$

250 census data, $2^{\text {nd }}$ census data, and temporal changes in traits and neighborhood crowding data).

251 We developed a conceptual framework model that shows possible direct and indirect casual

252 relationships among predictors and response variable (Figure S3). These hypothesized

253 relationships help to optimize the piecewise SEMs. Functional traits, initial DBH size and

254 neighborhood crowding were predictor variables, whereas relative growth rate of individuals was

255 a response variable. Species were taken as random effects in our piecewise SEMs analysis. To

256 minimize model complexity, functional traits were reduced using PCA and we used the first two

257 PCA axes representing traits as predictors. A series of piecewise SEMs were fit to the data, and

258 insignificant pathways were removed progressively from models to improve fitness of the model.

259 We used Fishers's C statistics to evaluate the goodness fit of the models with high P-values

260 showing good fit (Lefcheck 2016). We used AIC to select the best fit and parsimonious model.

261 We used R version 3.5.3 to run all the analyses. 'Ime4' package was used to fit linear

262 mixed-effect models (Pinheiro and Bates. 2016). Principal component analysis was conducted

263 with the 'rda' function in vegan package (Oksanen et al. 2014). We used 'psem' function in

264 'piecewiseSEM' package for piecewise SEMs analysis (Lefcheck 2016).

266 RESULTS

267 Temporal shifts in trait values, growth and neighborhood crowding

268 We tested the extent of trait, growth and neighborhood variation at the individual level and

269 temporal time points in a tropical forest. We found significant temporal changes in trait values

270 for at least half of the functional traits being tested (Figure 1; see also Figure S4 that compares

271 individual traits on the scatter plot). SLA decreased significantly from the first census to the 
272 second census, whereas leaf chlorophyll content, leaf dry mass and leaf succulence increased

273 from the first to the second census. However, we did not find significant temporal changes in

274 trait values for Leaf fresh mass, Leaf thickness, Leaf area, and LDMC. Individuals’ size,

275 expressed as DBH, also increased significantly over time indicating significant growth of focal

276 trees, whereas significant change was not observed on the neighborhood crowding of individuals,

277 consistent with the late-successional stage of the forest.

278 We also analyzed the amount of trait variation explained by the species, individuals,

279 years and leaves. We found that most functional traits showed significant variation among

280 leaves, individuals, species and between census years (Figure 2). Most functional trait variations

281 are explained by the species followed by the individual level.

283 Axes of functional variation

284 To evaluate trait associations and plant strategies, we used a PCA of the seven traits of species

285 (Figure 3). The first two PCA axes explained almost $66 \%$ of the variation and showed a

286 spectrum of trait variation. The first PCA axis shows species with a large leaf area, leaf thickness

287 and dry mass at the left to species with high SLA at the right. The second axis represents species

288 with high chlorophyll content at the top to species with high LDMC and succulence at the

289 bottom. These axes, therefore, represent the leaf trait spectrum tradeoff. We also conducted the

290 PCA on the temporal change in traits (trait values in 2010 were subtracted from traits in 2017) to

291 see axes of temporal plasticity (Figure S5). Along the first axis, individuals were separated

292 between those species with decreasing SLA and leaf area on the right-hand side and those with

293 increasing leaf dry mass on the left side. Species with high leaf thickness and succulence were

294 represented at the top of the second axis. 


\section{Effect of traits and neighborhood crowding on the relative growth rate of individual trees}

296 We tested how growth was correlated with temporal variation of traits and neighborhood

297 crowding. We found that traits and neighborhood crowding have not explained significantly the

298 relative growth rate of individual trees in the first census (Figure 4a). However, in the second

299 census leaf chlorophyll content, leaf area, leaf dry mass, LDMC, leaf succulence and

300 neighborhood crowding significantly explained the relative growth rate of individuals (Figure

$3014 b)$. We also used the temporal changes in functional traits and neighborhood crowding to

302 predict the growth rate of individuals, and interestingly found that almost all of the change in

303 trait values and neighborhood crowding explained better the relative growth rate of the

304 individuals (Figure 4c). See Table S5, S6, and S7 for model AIC values.

305 We also used SEMs to investigate any possible pathways by which traits and

306 neighborhood crowding has interactively predicted growth of individuals. We found no

307 significant causal relationships among traits, neighborhood crowding and initial DBH size to

308 determine individuals' growth rates (Figure S6). However, initial DBH size (in addition to its

309 direct significant negative effect on RGR) has indirect significant positive effect on the RGR of

310 individuals through its negative effect on PC1 and PC2 of the second census and temporal

311 change data (Figure S6 b \& c). We also found initial DBH to negatively be interacted with

312 neighborhood crowding which in turn negatively influenced the RGR of individuals in the

313 temporal change data (Figure S6 c). However, we did not find a pathway through which

314 neighborhood crowding and traits interactively affect individuals' growth in all census data. 


\section{DISCUSSION}

319 While past studies of community functional dynamics have focused on turnover in species

320 identity, here we show patterns arising due to temporal trait plasticity of long-lived individuals.

321 We predicted individual tree growth using traits measured on individuals while considering at

322 the same time the biotic context in which that individual was found across time points. We

323 showed trait-growth relationships, and negative effects of neighborhood crowding on the growth

324 rate of individuals. The significant change of traits over time (temporal trait plasticity) and the

325 association of functional traits with the leaf economics spectrum was also detected. Half of the

326 functional traits measured changed significantly over time and were able to predict individual

327 growth rates. The covariation of traits also revealed the presence of, to a certain extent, a leaf

328 economics spectrum.

\section{Temporal trait plasticity and neighborhood crowding}

331 Tropical forests inhabit dynamic environments, and therefore some changes in functional

332 strategies of trees might be adaptive. Consistently, we found significant temporal changes of

333 some functional traits in our plot that could potentially alter individual ecological requirements.

334 SLA decreased and leaf dry mass increased, possibly suggesting a change in strategies for

335 resource acquisition. Similar observations have been previously reported using data on turnover

336 in species identities and assuming fixed trait values for species. For example, in Neotropical

337 forests changes in species composition over time shifted toward conservative functional

338 strategies, mainly due to disturbances (Van Der Sande et al. 2016). Muscarella et al. (2017) also

339 found that communities shifted from species with resource acquisitive to conservative functional

340 strategies in Mexico. Disturbances like tree fall and landslides have been common on the 
341 topographically steep plot, potentially influencing the tree community (Hu et al. 2012),

342 especially Ficus species which tend to be found on the slopes. Furthermore, as species grow

343 larger, larger amounts of energy could be invested to build non-photosynthetic tissue of the plant

344 to maximize survival (King 2011). Thus, the formation of high leaf dry mass and succulent

345 leaves over time could protect species from herbivore and pathogen attack, and provide

346 mechanical support that maximize the life span of leaves and individual trees (Kitajima and

347 Poorter 2010, Onoda et al. 2011, Poorter et al. 2018). The temporal development of this

348 functional strategy could be associated with the resource distribution of the plot. The steep slopes

349 of the plot, where most of the study Ficus species are distributed, have poor soil nutrients (Hu et

350 al. 2012). These poor soils might influence the species to gradually develop more conservative

351 traits (low SLA and leaf area, high leaf dry mass and leaf succulence) to maximize investment on

352 structural components (minimize construction costs) and survival rate. Similarly, a long-term

353 shift in functional composition due to species turnover (increased leaf area and SLA, decreased

354 leaf succulence and wood density) was reported in a tropical dry forest (Swenson et al. 2020).

355 Therefore, the observed temporal changes in trait values in our study, regardless of the direction

356 (decreasing or increasing) reflects that the system of the forest is highly dynamic.

357 We also used the PCA of these traits to explore species functional strategies. The first

358 two PCA axes explained $66 \%$ of the variation, and we found two lines of trait variation showing

359 the ecological strategies of plants. The first axis corresponded to species with high SLA at one

360 extreme, versus species with high leaf thickness and area at the other extreme. The second axis

361 corresponded to species with high leaf chlorophyll content versus high leaf dry matter and

362 succulent leaves. This resource use strategy trade-off is a common phenomenon in the tropical

363 trees and is well documented (Wright et al. 2004, Katabuchi et al. 2012, Asefa et al. 2017). The 
364 negative correlation of SLA and leaf area might suggest that these two important traits were not

365 integrated to determine the growth performance of the species (Poorter et al. 2018). Similarly,

366 SLA and leaf area were found to be negatively correlated, probably indicating that costs to

367 deploy SLA for large leaves was more expensive than small leaves (Milla and Reich 2007). The

368 negative correlation of SLA with leaf thickness and/or positive correlation of LDMC with leaf

369 thickness and succulence suggested that thick leaves maximize the longevity of trees by

370 providing protection from herbivore attack, pathogens and physical damage. In summary, the

371 functional trait variation of Ficus species supports the globally known leaf economics spectrum.

372 We also determined the factors associated with the greatest portion of functional trait

373 variation. All traits were varied significantly among individuals within species and among

374 different species. However, the largest extent of trait variations was mainly explained by species

375 identity, with a range of $23.39 \%$ for leaf fresh mass to $58.49 \%$ for LDMC, suggesting that trait

376 variation was stronger at the species level than the individual level. The species differences in

377 traits might be enhanced by niche-driven evolutionary trait divergence among different species.

378 Phylogenetically conserved traits might show small trait variation within species, suggesting less

379 trait plasticity among individuals (Poorter et al. 2018). The detection of significant individual

380 trait variation, however, in general highlights ecological difference among individuals. A

381 previous study also indicated the variation of Ficus traits at the individual level, reflecting

382 differences of ecological requirements among individuals co-occurring together at small scales

383 (e.g. $10 \mathrm{~m}$ ) (Lasky et al. 2014a). Our result highlights that individual trait variation supports the

384 species level variation of functional traits suggesting that both the individual and species level

385 approach together helps to better understand community dynamics. 


\section{Effect of traits on the relative growth rate of individuals}

388 We tested to what extent individual trait variation predicts the individual variation of growth

389 rate. The relative growth rate of individuals was found to vary substantially among individuals of

390 the same species and among different species (Figure S2). We found that initial DBH has

391 consistent relationships with growth of individuals in both censuses. Our results indicate that the

392 relationship between functional traits and relative growth rate varied through time. Functional

393 traits measured at the first census did not predict the growth rates of individuals. However,

394 in the second census, leaf dry mass, LDMC and leaf area negatively predicted individuals'

395 growth rates, whereas chlorophyll content and leaf succulence were positively associated with

396 the growth rate of individuals.

397 Detection of weak trait-growth relationships in the first census could be attributed to

398 different factors. Using stem tree diameter as a growth indicator might be a poor parameter to

399 describe the entire plant growth pattern, especially for small plants due to the fact that plants

400 could invest their energy in height and leaf growth to capture adequate amount of sunlight as

401 height growth is more ecologically important than diameter growth, or underground investment

402 to maximize nutrient acquisition (Paine et al. 2015, Poorter et al. 2018). The trait-growth

403 relationship might also be confounded by developmental stages of trees, as ontogenetic stages of

404 trees were found to determine trait-growth relationships (Iida et al. 2014, Lasky et al. 2015,

405 Visser et al. 2016), suggesting size-dependent changes in growth strategies (Gibert et al. 2016).

406 However, these developmental differences should be relatively subtle given the short time

407 interval between censuses (7 years) relative to the lifespan of many trees (many decades).

408 The relative growth rate of individuals in the second census, however, was found to be

409 positively correlated with SLA and chlorophyll content of the species. This is consistent with the 
410 expectation that high chlorophyll content and SLA are considered to maximize the efficiency of

411 biomass investment for light interception (Poorter et al. 2008). Similarly, Poorter and Bongers

412 (2006) found that SLA predicted higher growth rate of rainforest species. Lack of consistent

413 predictive power of traits on the relative growth rate of individuals over time points in this study,

414 however, might indicate how sensitive tropical forests are to the temporal dynamics of the

415 environment or trait plasticity, indicating the importance of complexity and temporal dynamics

416 in tropical rainforests. However, temporal trait plasticity did explain the relative growth rate of

417 individuals. Increases in leaf chlorophyll content and leaf succulence over time had positive

418 correlations with growth, while a decrease in leaf area, leaf dry mass and LDMC over time had a

419 negative effect on growth, suggesting that temporal shifts in trait values appeared to be more

420 predictive of growth rate than initial census trait values. These functional traits showed large

421 variation across time points and subsequently were found to be growth determinants.

422 Considering the effect of temporal trait plasticity helps to better predict growth dynamics of

423 trees. Our findings in general highlight that considering the dynamic ecological dimension of

424 species such as traits, helps to gain a temporal understanding of plant growth dynamics.

425 We also found both direct and indirect effects of initial DBH of trees on the growth rate

426 of individuals from our SEMs analyses. Initial DBH of trees was found to directly negatively

427 affect the relative growth rate of individuals, as we found in the mixed effects models. This

428 might be because small adult size plants could allocate more resources to height than diameter

429 growth, as height is more important for interception of light resource (Paine et al. 2015).

430 However, initial DBH of trees indirectly positively affected the relative growth rate of trees

431 through its significant negative effect on PC1 and PC2 in the second census and PC1 in the

432 temporal change data. The PC1 both in the second and temporal change data were mostly 
433 represented by leaf dry mass and LDMC, while SLA and succulence were largely represented by

434 PC2 in the second census data (Table S8). Initial DBH size of trees could be negatively related

435 with resource conservative traits mentioned above that may provide protection against herbivores

436 and pathogens (Van Der Sande et al. 2016). Plants could prioritize their survival by building

437 non-photosynthetic tissues particularly at small adult size at which susceptibility to herbivory

438 and physical damages is higher. This reduces mortality and maximizes the longevity of trees

439 (Onoda et al. 2011), and provides time for trees to gradually shift to the strategy by which more

440 energy could be invested for their growth rates (Iida et al. 2014). Consistently, our result may

441 demonstrate that initial DBH size of trees could indirectly promote the growth rate of individuals

442 in a long-term by controlling trait expressions in response to many biotic and abiotic factors.

443 Initial DBH size of trees also negatively interacted with neighborhood crowding to significantly

444 limit the RGR of individuals in the temporal change data. The crowding conditions of

445 individuals could be influenced by the size of neighboring trees. Large trees might dominate

446 small neighborhood individuals through competition thereby reducing neighborhood density

447 and/or limit individuals' growth, as they may have large canopy, crown and deep root systems

448 (Yang et al. 2020 in press). Our result therefore, suggests that various factors may interactively

449 influence species performance through multiple pathways.

\section{Effect of neighborhood crowding on the relative growth rate of individuals}

451 We evaluated the effect of neighborhood interactions on individual growth, and how the effect

452 changes over time. We found that neighborhood crowding significantly limits the growth rate of

453 individuals, which is consistent with previous studies (Bagchi et al. 2014, Lasky et al. 2014b,

454 Fortunel et al. 2016, Liu et al. 2016, Fortunel et al. 2018, Umaña et al. 2018). Also, species-

455 specific negative density dependence was found to drive seedling survival (Lin et al. 2012). This 
456 further confirmed our result that species growth might be influenced by biotic interaction with

457 neighbors. Interestingly, our result demonstrates not only the negative effect of neighborhood

458 crowding on growth but also its effect found to vary through time.

459 Similarly, the growth rate of individuals was negatively affected by changes in the

460 number of conspecifics over time (Umaña et al. 2018). We detected a coordinated shift (temporal

461 plasticity) of species from acquisitive to conservative, which may enhance the density-dependent

462 effect of neighbors on growth rate due to niche overlap (Uriarte et al. 2010). However, the effect

463 of neighborhood crowding on individuals' performance in the first census was not significant,

464 suggesting that interactions between tree neighbors might not be consistent over time. This

465 inconsistency may be related to trait differences among individuals, which was may be an

466 important mechanism of coexistence (Lasky et al. 2014a). The relationship of growth and

467 neighborhood competition might not be completely captured under current environmental

468 dynamics. As a result, it is always a challenge to explore the effect of neighborhood competition

469 dynamics on the tree performance unless a temporal change in local neighbor density is

470 considered. We found that temporal changes in neighborhood crowding affected tree growth,

471 suggesting the importance of the approach we used to test the impact of temporal shifts of

472 neighborhood competition on the demography of species. The result of this study highlights the

473 importance of the temporal dimension of ecology to understand better how species interactions

474 change over time and predict individual performance.

475 In conclusion, our result demonstrates that functional traits and neighborhood crowding

476 have changed over time. This temporal trait plasticity was found to best predict the growth rate

477 of individuals. Neighborhood interactions also limited the growth of individuals. This all

478 together suggested that the temporal dynamics of traits and biotic interactions need to be 
479 considered to explain better the growth dynamics of tropical trees. Furthermore, trees tended to

480 shift their functional strategies from being acquisitive to conservative, as we observed the

481 increment of leaf dry mass and succulence, and decrement of SLA and leaf area through time

482 points. We also found major axes of tree functional strategies in PCA, highlighting potentially

483 adaptive trait differences. This study in general highlights that a temporal-based approach of

484 investigating the relationship between traits and biotic interactions, and growth for each

485 individual tree, can help gain insights into forest dynamics. To better predict future changes in

486 community structure, function and dynamics, it is therefore important to consider the temporal

487 change of environments together with changes in traits and biotic interactions over time, as trait-

488 neighborhood-performance relationships vary temporally with environmental conditions.

490 ACKNOWLEDGMENTS

491 This research was supported by the Strategic Priority Research Program of the Chinese Academy

492 of Sciences (XDB31000000), National Natural Science Foundation of China (31800353 and

493 31670442), the CAS 135 program (No. 2017XTBG-T01), the Chinese Academy of Sciences

494 Youth Innovation Promotion Association (2016352), the Southeast Asia Biodiversity Research

495 Institute, Chinese Academy of Sciences (Y4ZK111B01), the West Light Foundation of the

496 Chinese Academy of Sciences, and the "Ten Thousand Talents Program of Yunnan” (YNWR-

497 QNBJ-2018-309). Data collection in 2010 was supported by a U.S. National Science Foundation

498 East Asia Pacific Summer Institute fellowship, and a Casey Stengl research fellowship from the

499 Graduate Program in Ecology, Evolution, and Behavior at the University of Texas-Austin to

500 JRL. 


\section{AUTHORS' CONTRIBUTIONS}

503 MA, YJ and XS designed the study; YJ, JRL and XS collected the field data; MA, YJ and XS

504 analyzed the data; MA, YJ, XS and JRL wrote the manuscript, and all authors provided

505 comments.

506

507 DATA AVAILABILITY STATEMENT

508 Data will be available online upon manuscript acceptance.

\section{REFERENCES}

511 Adler, P. B., A. Fajardo, A. R. Kleinhesselink, and N. J. B. Kraft. 2013. Trait-based tests of 512 coexistence mechanisms. Ecology Letters 16:1294-1306.

513 Asefa, M., M. Cao, G. Zhang, X. Ci, J. Li, and J. Yang. 2017. Environmental filtering structures

514 tree functional traits combination and lineages across space in tropical tree assemblages.

$515 \quad$ Scientific Reports 7.

516 Bachelot, B., R. K. Kobe, and C. Vriesendorp. 2015. Negative density-dependent mortality

517 varies over time in a wet tropical forest, advantaging rare species, common species, or no 518 species. Oecologia 179:853-861.

519 Bagchi, R., R. E. Gallery, S. Gripenberg, S. J. Gurr, L. Narayan, C. E. Addis, R. P. Freckleton, 520 and O. T. Lewis. 2014. Pathogens and insect herbivores drive rainforest plant diversity and $521 \quad$ composition. Nature 506:85-88.

522 Baythavong, B. S. 2011. Linking the spatial scale of environmental variation and the evolution of 523 phenotypic plasticity: Selection favors adaptive plasticity in fine-grained environments. 
American Naturalist 178:75-87.

525 Cao, M., X. Zou, M. Warren, and H. Zhu. 2006. Tropical forests of xishuangbanna, china.

$526 \quad$ Biotropica $38(3): 306-309$.

527 Chen, Y. C., S. J. Wright, H. C. Muller-Landau, S. P. Hubbell, Y. Wang, and S. Yu. 2016.

528 Positive effects of neighbourhood complementarity on tree growth in a neotropical

529 forest.pdf. Ecology 97:776-785.

530 Comita, L. ., H. C. Muller-Landau, S. Aguilar, and S. P. Hubbell. 2010. Asymmetric Density

531 Dependence Shapes Species Abundances in a Tropical Tree Community. Science 329:330-

$532 \quad 332$.

533 Condit, R. 1998. Tropical forest census plots: methods and results from Barro Colorado Island,

534 Panama and a comparison with other plots. Springer, Berlin Heidelberg New York.

535 Cornelissen, J. H. C., J. S. Lavorel, E. Garnier, S. Díaz, N. Buchmann, D. E. Gurvich, P. B.

536 Reich, H. ter Steege, H. D. Morgan, M. G. A. van der Heijden, J. G. Pausas, and H. Poorter.

537 2003. A handbook of protocols for standardised and easy measurement of plant functional

538 traits worldwide. Australian Journal of Botany 51:335-380.

539 Coste, S., C. Baraloto, C. Leroy, É. Marcon, A. Renaud, A. D. Richardson, J. Roggy, H.

540 Schimann, J. Uddling, and B. Herault. 2010. Assessing foliar chlorophyll contents with the

541 SPAD-502 chlorophyll meter $\square$ : a calibration test with thirteen tree species of tropical

542 rainforest in French Guiana. Annals of Forest Science 67:1-5.

543 Dudley, S. A., and J. Schmitt. 1996. Testing the adaptive plasticity hypothesis: Density-

544 dependent selection on manipulated stem length in Impatiens capensis. The American

$545 \quad$ Naturalist 147:445-465.

546 Enquist, B. J., and C. A. F. Enquist. 2011. Long-term change within a Neotropical forest: 
Assessing differential functional and floristic responses to disturbance and drought. Global Change Biology 17:1408-1424.

Fauset, S., T. R. Baker, S. L. Lewis, T. R. Feldpausch, K. Affum-Baffoe, E. G. Foli, K. C. and distribution in a diverse Amazonian forest. Ecology 99:2272-2283.

555 Fortunel, C., S. J. Wright, and N. C. Garwood. 2016. Functional trait differences influence neighbourhood interactions in a hyperdiverse Amazonian forest. Ecology Letters 19:1062-

Garnier, E., and G. Laurent. 1994. Leaf anatomy, specific mass and water content in congeneric annual and perennial grass species. New Phytologist 128:725-736.

Ghalambor, C. K., J. K. McKay, S. P. Carroll, and D. N. Reznick. 2007. Adaptive versus nonadaptive phenotypic plasticity and the potential for contemporary adaptation in new functional traits and growth rate: meta-analysis shows effects change with plant size, as predicted. Journal of Ecology 104:1488-1503.

567 Hu, Y.-H., L.-Q. Sha, F. G. Blanchet, J.-L. Zhang, Y. Tang, G.-Y. Lan, and M. Cao. 2012.

568 Dominant species and dispersal limitation regulate tree species distributions in a 20-ha plot in Xishuangbanna, southwest China. Oikos 123:952-960. 
570 Iida, Y., T. S. Kohyama, N. G. Swenson, S. H. Su, C. T. Chen, J. M. Chiang, and I. F. Sun. 2014.

$571 \quad$ Linking functional traits and demographic rates in a subtropical tree community: The

572 importance of size dependency. Journal of Ecology 102:641-650.

573 Johnson, D. J., R. Condit, S. P. Hubbell, and L. S. Comita. 2017. Abiotic niche partitioning and 574 negative density dependence drive tree seedling survival in a tropical forest. Proceedings of 575 the Royal Society B: Biological Sciences 284.

576 Katabuchi, M., H. Kurokawa, S. J. Davies, S. Tan, and T. Nakashizuka. 2012. Soil resource

577 availability shapes community trait structure in a species-rich dipterocarp forest. Journal of $578 \quad$ Ecology 100:643-651.

579 Katabuchi, M., S. J. Wright, N. G. Swenson, K. J. Feeley, R. Condit, S. P. Hubbell, and S. J.

580 Davies. 2017. Contrasting outcomes of species- and community-level analyses of the 581 temporal consistency of functional composition. Ecology 98:2273-2280.

582 King, D. A. 2011. Size-related changes in tree proportions and their potential influence on the 583 course of height growth. Size- and Age-Related Changes in Tree Structure and

584 Function((eds F.C.C. Meinzer, B. Lachenbruch, T.E.E. Dawson, F.C. Meinzer \& €U.

585 Niinemets). pp. 165-191. Springer, Dordrecht, the Netherlands.

586 Kitajima, K., and L. Poorter. 2010. Tissue-level leaf toughness, but not lamina thickness , 587 predicts sapling leaf lifespan and shade tolerance of tropical tree species. New Phytologist $588 \quad 186: 708-721$.

589 Van Kleunen, M., and M. Fischer. 2005. Constraints on the evolution of adaptive phenotypic 590 plasticity in plants. New Phytologist 166:49-60.

591 Kunstler, G., S. Lavergne, B. Courbaud, W. Thuiller, G. Vieilledent, N. E. Zimmermann, J.

592 Kattge, and D. A. Coomes. 2012. Competitive interactions between forest trees are driven 
by species' trait hierarchy, not phylogenetic or functional similarity: Implications for forest community assembly. Ecology Letters 15:831-840.

Lamanna, J. A., S. A. Mangan, A. Alonso, N. A. Bourg, W. Y. Brockelman, S. Bunyavejchewin, diversity increases with the strength of negative density dependence at the global scale.

Lan, G., H. Zhu, M. Cao, Y. Hu, H. Wang, X. Deng, S. Zhou, J. Cui, J. Huang, Y. He, L. Liu, H. $\mathrm{Xu}$, and J. Song. 2009. Spatial dispersion patterns of trees in a tropical rainforest in Xishuangbanna, southwest China. Ecological Research 24:1117-1124.

Lasky, J. R., B. Bachelot, R. Muscarella, N. Schwartz, J. Forero-Montaña, C. J. Nytch, N. G.

Lande, R., and S. J. Arnold. 1983. The Measurement of Selection on Correlated Characters. Swenson, J. Thompson, J. K. Zimmerman, and M. Uriarte. 2015. Ontogenetic shifts in trait-

608 Lasky, J. R., I. F. Sun, S.-H. Su, Z.-S. Chen, T. H. Keitt, and C. Canham. 2013. Trait-mediated mediated mechanisms of plant community assembly. Ecology 96:2157-2169.

611 Lasky, J. R., J. Yang, G. Zhang, M. Cao, Y. Tang, and T. H. Keitt. 2014a. The role of Functional traits and individual variation in the co-occurrence of Ficus species. Ecology 95:978-990.

613 Lasky, J. R., M. Uriarte, V. K. Boukili, and R. L. Chazdon. 2014b. Trait-mediated assembly

614 processes predict successional changes in community diversity of tropical forests.

615 Proceedings of the National Academy of Sciences of the United States of America 
617 Lázaro-Nogal, A., S. Matesanz, A. Godoy, F. Pérez-Trautman, E. Gianoli, and F. Valladares.

618 2015. Environmental heterogeneity leads to higher plasticity in dry-edge populations of a

619 semi-arid Chilean shrub: Insights into climate change responses. Journal of Ecology

$620 \quad 103: 338-350$.

621 Lefcheck, J. S. 2016. piecewiseSEM: Piecewise structural equation modelling in r for ecology,

622 evolution, and systematics. Methods in Ecology and Evolution 7:573-579.

623 Lin, L., L. S. Comita, Z. Zheng, and M. Cao. 2012. Seasonal differentiation in density-dependent

624 seedling survival in a tropical rain forest. Journal of Ecology 100:905-914.

625 Liu, X., N. G. Swenson, D. Lin, X. Mi, M. N. Umaña, B. Schmid, and K. Ma. 2016. Linking

626 individual-level functional traits to tree growth in a subtropical forest. Ecology 97:2396-

$627 \quad 2405$.

628 Laughlin, D. C., J. R. Gremer, P. B. Adler, R. M. Mitchell, and M. M. Moore. 2020. The Net

629 Effect of Functional Traits on Fitness (in press). Trends in Ecology \& Evolution.

630 https://doi.org/10.1016/j.tree.2020.07.010

631 Marenco, R. A., S. A. Antezana-Vera, and H. C. S. Nascimento. 2009. Relationship between

632 specific leaf area, leaf thickness, leaf water content and SPAD-502 readings in six

633 Amazonian tree species. Photosynthetic 47:184-190.

634 Milla, R., and P. B. Reich. 2007. The scaling of leaf area and mass $\square$ : the cost of light

635 interception increases with leaf size. Proc. R. Soc. B 274:2109-2114.

636 Moran, N. A. 1992. The Evolutionary Maintenance of Alternative Phenotypes. American

$637 \quad$ Naturalist 139:971-989.

638 Muscarella, R., M. Lohbeck, M. Martinez-Ramos, L. Poorter, J. E. Rodriguez-Velazquez, M. 
Van Breugel, and F. Bongers. 2017. Demographic drivers of functional composition dynamics. Ecology 98:2743-2750.

641 Newbery, D. M., and P. Stoll. 2013. Relaxation of species-specific neighborhood effects in

$642 \quad$ Bornean rain forest under climatic perturbation. Ecology 94:2838-2858.

643 Oksanen, J., F. G. Blanchet, R. Kindt, P. Legendre, P. R. Minchin, R. B. O’Hara, G. L. Simpson,

644 P. Solymos, M. H. H. Stevens, and H. Wagner. 2014. Package vegan: Community ecology

645 package. R package version 2.2-0. http://cran.r-project.org/web/packages/vegan/Pakeman,

646 R. J. 2004. Consistency.

647 Onoda, Y., M. Westoby, F. J. Clissold, J. H. C. Cornelissen, P. V. A. Fine, and J. Jerome. 2011.

648 Global patterns of leaf mechanical properties. Ecology Letters 14:301-312.

649 Paine, C. E. T., L. Amissah, H. Auge, C. Baraloto, M. Baruffol, N. Bourland, H. Bruelheide, K.

650 Daïnou, R. C. de Gouvenain, J. L. Doucet, S. Doust, P. V. A. A. Fine, C. Fortunel, J. Haase,

651 K. D. Holl, H. Jactel, X. Li, K. Kitajima, J. Koricheva, C. Martínez-Garza, C. Messier, A.

652 Paquette, C. Philipson, D. Piotto, L. Poorter, J. M. Posada, C. Potvin, K. Rainio, S. E.

653 Russo, M. Ruiz-jaen, M. Scherer-Lorenzen, C. O. Webb, S. J. Wright, R. A. Zahawi, and A.

654 Hector. 2015. Globally, functional traits are weak predictors of juvenile tree growth, and we 655 do not know why. Journal of Ecology 103:978-989.

656 Pigliucci, M. 2001. Phenotypic Plasticity: Beyond Nature and Nurture. Johns Hopkins University $657 \quad$ Press, Baltimore.

658 Pinheiro, J., and D. Bates. 2016. Package "nlme": Fit and compare Gaussian linear and nonlinear 659 mixed-effects models. Version 3.1-124. https://cran.r-project.org/web/packages/nlme/.

660 Poorter, L., and F. Bongers. 2006. Leaf traits are good predictors of plant performance across 53 661 rain forest species. Ecology 87:1733-1743. 
Poorter, L., C. V. Castilho, J. Schietti, R. S. Oliveira, and F. R. C. Costa. 2018. Can traits predict individual growth performance? A test in a hyperdiverse tropical forest. New Phytologist 219:109-121.

Poorter, L., and D. M. A. Rozendaal. 2008. Leaf size and leaf display of thirty-eight tropical tree species. Oecologia 158:35-46.

Poorter, L., S. J. Wright, H. Paz, D. D. Ackerly, R. Condit, E. Harms, J. C. Licona, S. J. Mazer, Rates? Evidence from Five Neotropical Forests Published by $\square$ : Ecological Society of

Seelig, H. D., R. J. Stoner, and J. C. Linden. 2012. Irrigation control of cowpea plants using the functional composition and diversity of a tropical dry forest: a 30-yr study. Ecological Monographs 90:1-16. Xishuangbanna, Southwest China. Biotropica 38:328-333. 
Umaña, M. N., L. Lin, E. F. Zipkin, C. Zhang, M. Cao, and N. G. Swenson. 2018. level trait variation and negative density dependence affect growth in tropical tree seedlings. Journal

Uriarte, M., J. R. Lasky, V. K. Boukili, and R. L. Chazdon. 2016. DEMOGRAPHY BEYOND impacts on successional dynamics of tropical rainforests. Functional Ecology 30:157-167.

Uriarte, M., N. G. Swenson, R. L. Chazdon, L. S. Comita, W. J. Kress, D. Erickson, J. F.Montana, J. K. Zimmerman, and J. Thompson5. 2010. Trait similarity, shared ancestry and the structure of neighbourhood interactions in a subtropical wet forest $\square$ : implications for

Visser, M. D., M. Bruijning, S. J. Wright, H. C. Muller-Landau, E. Jongejans, L. S. Comita, H. De Kroon, and H. de Kroon. 2016. Functional traits as predictors of vital rates across the

Wade, M. J., and S. Kalisz. 1990. The Causes of Natural Selection. Evolution 44:1947-1955.

Worthy, S. J., and N. G. Swenson. 2019. Functional perspectives on tropical tree demography and forest dynamics. Ecological Processes 4:1-11.

701 Wright, I. J., P. B. Reich, M. Westoby, D. D. Ackerly, Z. Baruch, F. Bongers, J. Cavender-Bares,

702 T. Chapin, J. H. C. Cornellssen, M. Diemer, J. Flexas, E. Garnier, P. K. Groom, J. Gulias,

703 K. Hikosaka, B. B. Lamont, T. Lee, W. Lee, C. Lusk, J. J. Midgley, M. L. Navas, Ü. economics spectrum. Nature 428:821-827.

Wright, S. J. 2002. Plant diversity in tropical forests: a review of mechanisms of species 
coexistence. Oecologia 130:1-14.

709 Wright, S. J., K. Kitajima, N. J. B. Kraft, P. B. Reich, I. J. Wright, D. E. Bunker, R. Condit, J. W.

710 Dalling, S. J. Davies, S. Di’Az, B. M. J. Engelbrecht, K. E. Harms, S. P. Hubbell, C. O.

711 Marks, M. C. Ruiz-Jaen, C. M. Salvador, And A. A. E. Zanne. 2010. Functional traits and

712 the growth - mortality trade-off in tropical trees. Ecology 91:3664-3674.

713 Yang, J., M. Cao, and N. G. Swenson. 2018. Why Functional Traits Do Not Predict Tree

714 Demographic Rates. Trends in Ecology \& Evolution 33:326-336.

715 Yang, J., S. Xiaoyang, Z. Jenny, C. Yuxin, C. Min, D. Xiaobao, Z. Wenfu, Y. Xiaofei, Z.

716 Guochen, T. Yong, and N. G. Swenson. 2020. Intra-specific variation in tree growth

717 responses to neighborhood composition and seasonal drought in a tropical forest (in press).

$718 \quad$ Journal of Ecology. https://doi.org/10.1111/1365-2745.13439

719 Zambrano, J., P. Marchand, and N. G. Swenson. 2017. Local neighbourhood and regional

720 climatic contexts interact to explain tree performance. Proc. R. Soc. B 284:201705.

721 Zhu, Y., L. S. Comita, S. P. Hubbell, and K. Ma. 2015. Conspecific and phylogenetic density-

722 dependent survival differs across life stages in a tropical forest. Journal of Ecology

$723 \quad 103: 957-966$. 


\section{FIGURE LEGENDS}

733 Figure 1. Comparison of trait values, growth and neighborhood crowding between the two

734 census years. Asterisk (*) indicates significant differences between the censuses for each

735 functional trait. DBH-Diameter at breast height.

736 Figure 2. Variance in trait values explained by species, individuals, census interval, and leaves.

737 Figure 3. PCA representing multivariate associations among functional traits of the 472 Ficus

738 individuals. The numbers in parentheses in the PC1 and PC2 axes are the variances explained by

739 each axis.

740 Figure 4. Standardized regression coefficients modelling initial size effects, traits and

741 neighborhood effects on tree relative growth rate. (a) the first census of traits and neighborhood

742 effect; (b) the second census of traits and neighborhood effect; (c) the effect of the change in

743 traits and neighborhood crowding values (the trait values in 2010 were subtracted from traits in

744 2017) on the relative growth rate of individuals during seven years. Circles indicate posterior

745 medians for each studied parameter and lines indicate $95 \%$ confidence intervals, with filled

746 circles representing significant effect. 
bioRxiv preprint doi: https://doi.org/10.1101/2020.09.11.292615; this version posted September 11, 2020. The copyright holder for this preprint (which was not certified by peer review) is the author/funder, who has granted bioRxiv a license to display the preprint in perpetuity. It is made available under aCC-BY-NC-ND 4.0 International license.
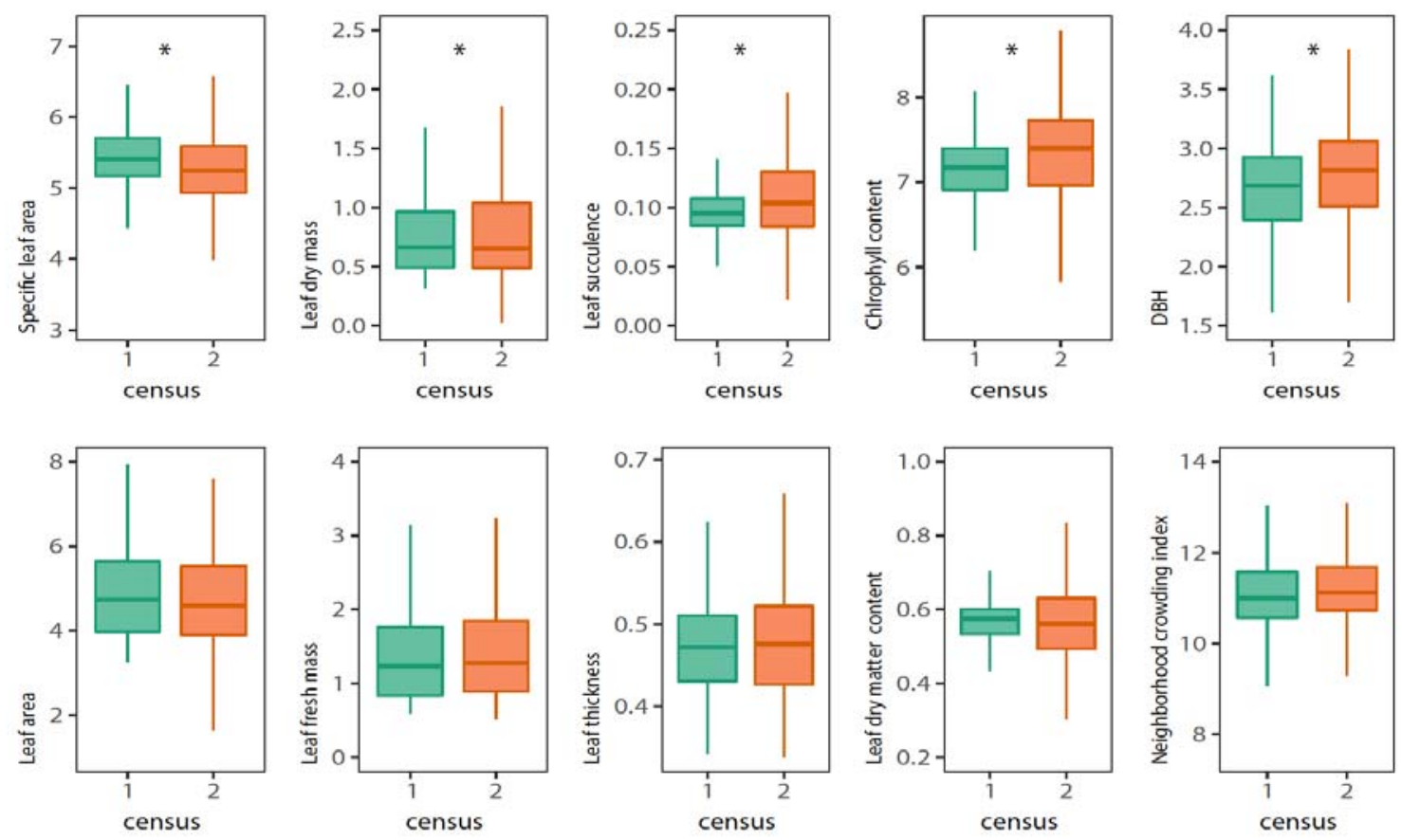

Figure 1

751 
bioRxiv preprint doi: https://doi.org/10.1101/2020.09.11.292615; this version posted September 11, 2020. The copyright holder for this preprint (which was not certified by peer review) is the author/funder, who has granted bioRxiv a license to display the preprint in perpetuity. It is made available under aCC-BY-NC-ND 4.0 International license.

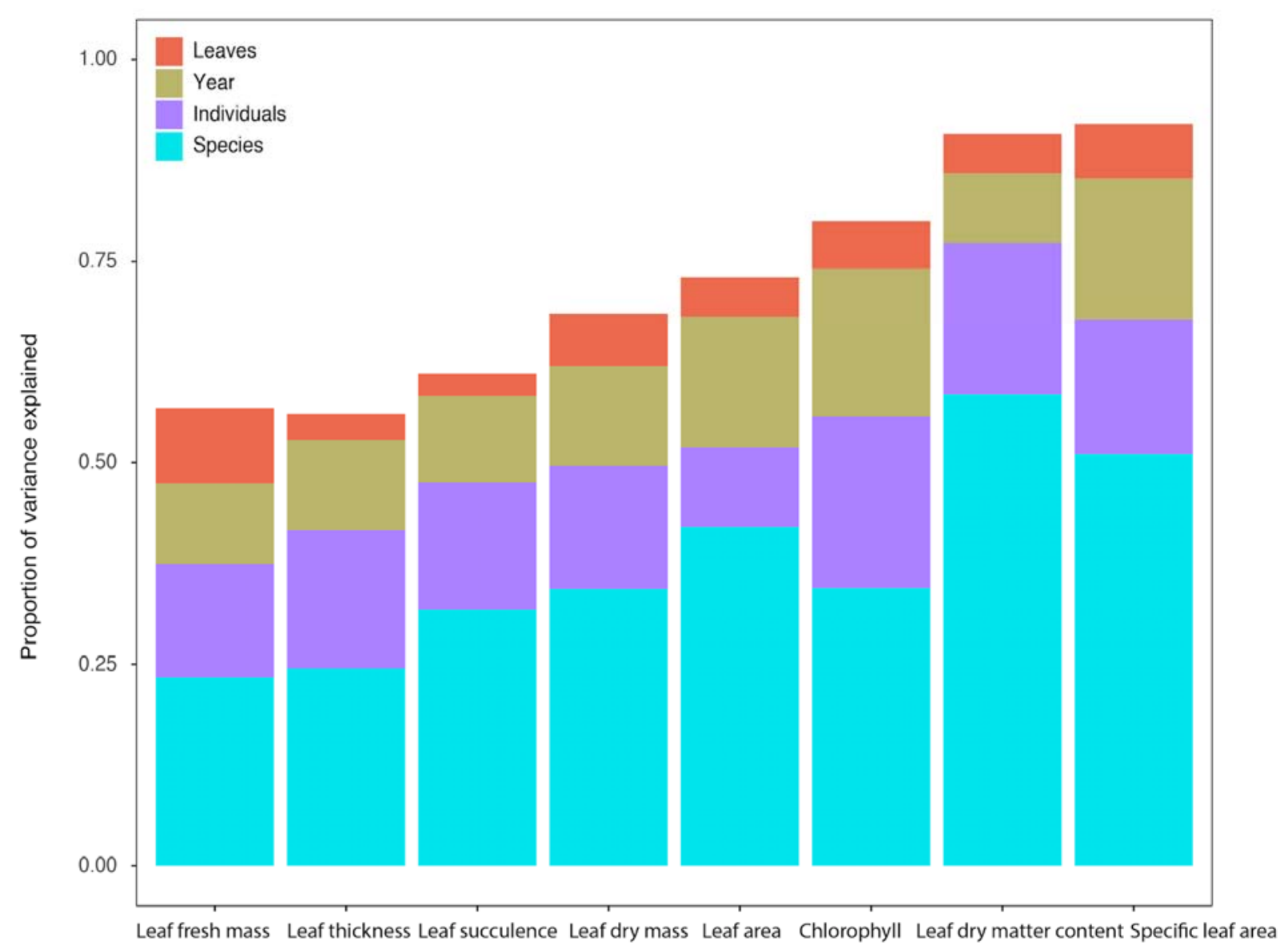

753 Figure 2 
bioRxiv preprint doi: https://doi.org/10.1101/2020.09.11.292615: this version posted September 11. 2020. The copvriaht holder for this preprint (which was not certified by peer review) is the author/funder, who has granted bioRxiv a license to display the preprint in perpetuity. It is made available under aCC-BY-NC-ND 4.0 International license.

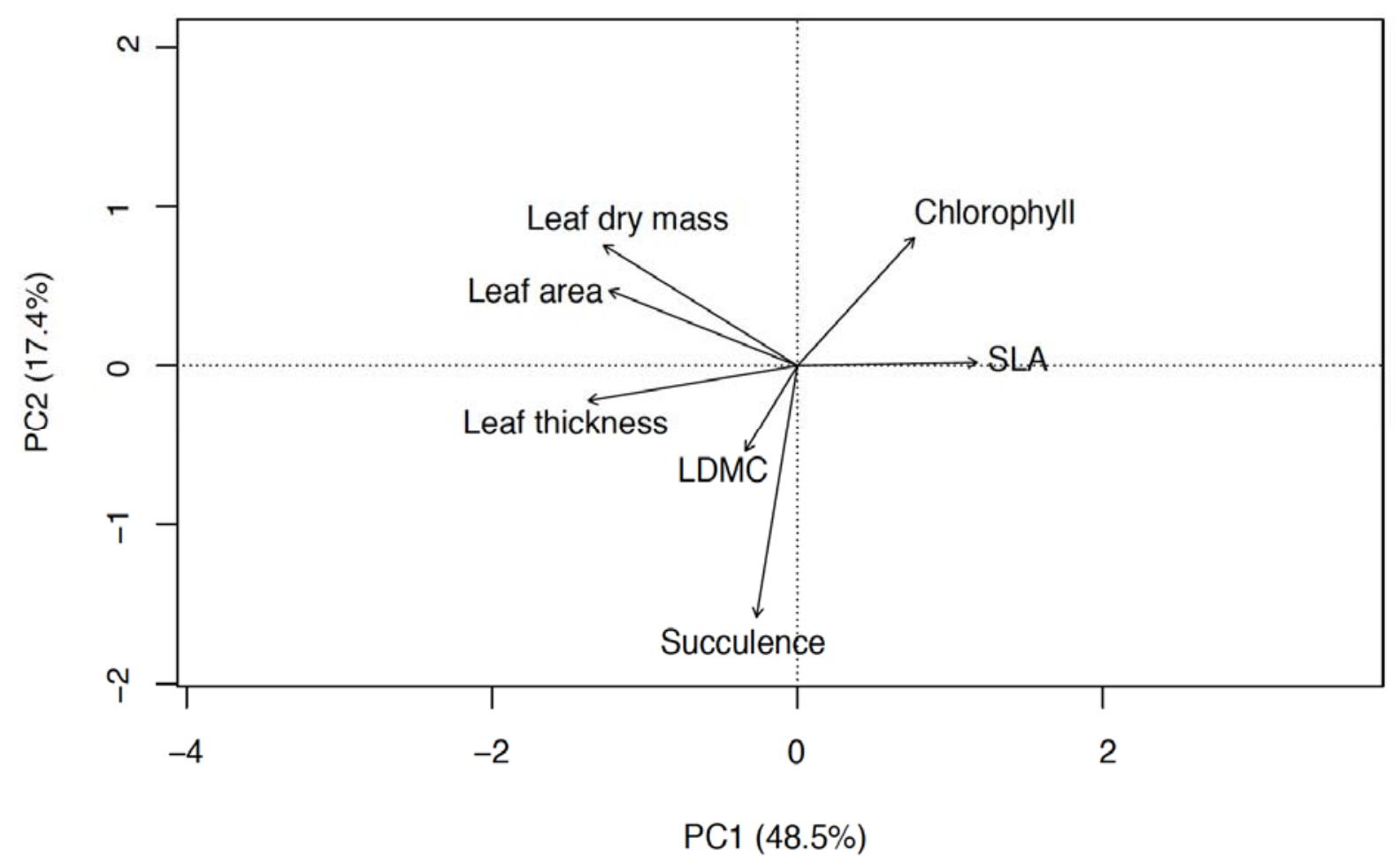

Figure 3 
bioRxiv preprint doi: https://doi.org/10.1101/2020.09.11.292615; this version posted September 11, 2020. The copyright holder for this preprint (which was not certified by peer review) is the author/funder, who has granted bioRxiv a license to display the preprint in perpetuity. It is made available under aCC-BY-NC-ND 4.0 International license.

(a) Neighborhood crowding index-

Leaf succulenceLeaf dry matter content-

Specific leaf area-

Leaf area-

Leaf thickness-

Leaf dry mass-

Chlorophyll content-

(b)

Neighborhood crowding index-

Leaf succulence-

Leaf dry matter content-

Specific leaf area-

Leaf area-

Leaf thickness-

Leaf dry mass-

Chlorophyll content-

(c)

Neighborhood crowding index-

Leaf succulence-

Leaf dry matter content-

Specific leaf area-

Leaf area-

Leaf thickness-

Leaf dry mass-

Chlorophyll content-

$\mathrm{DBH}$ -

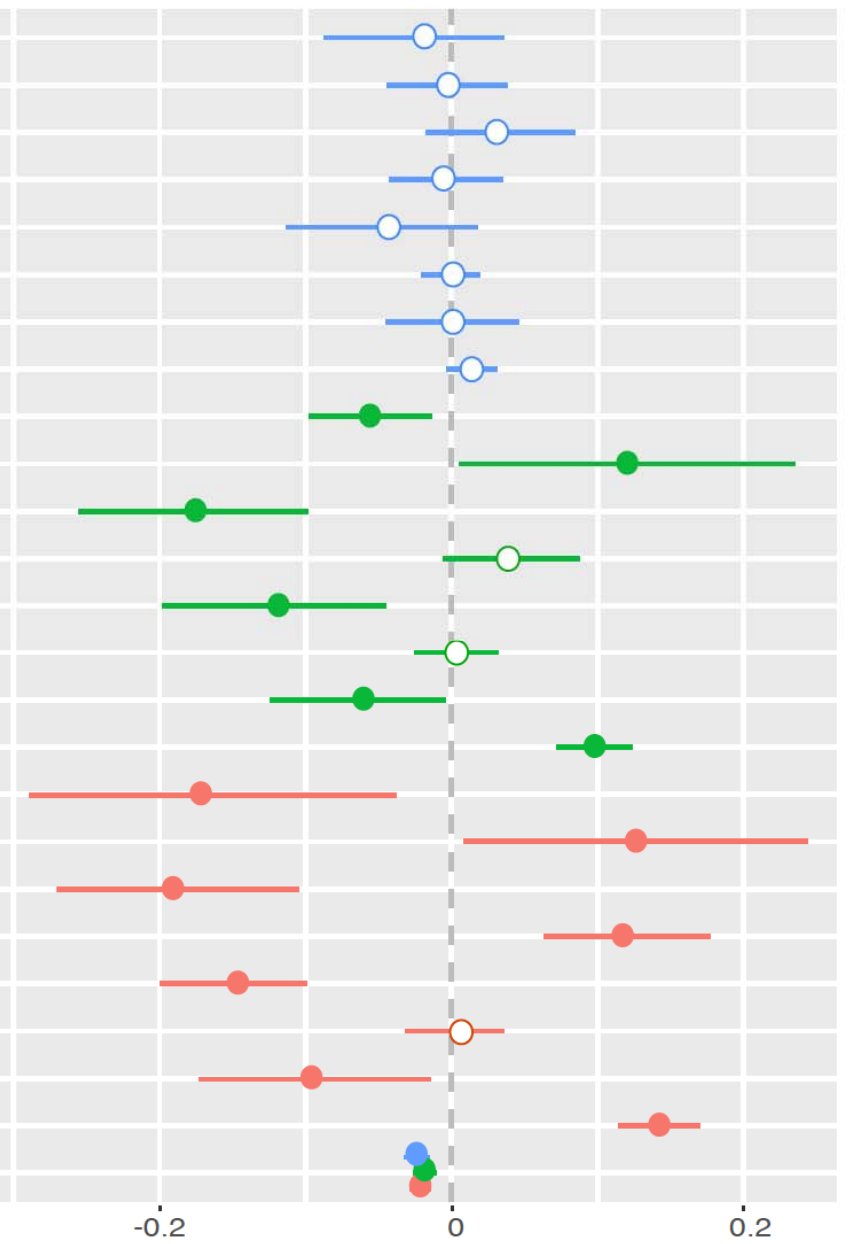

757 Figure 4

758

759

760

761

762

763

764

765 
766 Supporting information

767 Figure S1. Location map of the study area

768 Figure S2. Relative growth rate of species

769 Figure S3. Framework of the structural equation model

770 Figure S4. Scatter plot of functional traits

771 Figure S5. PCA showing axes of temporal trait plasticity

772 Figure S6. Piecewise structural equation model showing trait, DBH, and neighborhood

773 relationship with growth

774 Table S1. List of Ficus species

775 Table S2. Pearson correlation of traits in the first census

776 Table S3. Pearson correlation of traits in the second census

777 Table S4. Pearson correlation of temporal changes in traits

778 Table S5. AIC values of mixed-effect models in the first census

779 Table S6. AIC values of mixed-effect models in the second census

780 Table S7. AIC values of mixed-effect models of the temporal change in traits and NCI

781 Table S8. Trait loads on the PCA axes 